\title{
Adult lactose digestion status and effects on disease
}

\author{
Andrew Szilagyi MD FRCPC
}

\author{
A Szilagyi. Adult lactose digestion status and effects on disease. \\ Can J Gastroenterol Hepatol 2015;29(3):149-156.
}

BACKGROUND: Adult assimilation of lactose divides humans into dominant lactase-persistent and recessive nonpersistent phenotypes. OBJECTIVES: To review three medical parameters of lactose digestion, namely: the changing concept of lactose intolerance; the possible impact on diseases of microbial adaptation in lactase-nonpersistent populations; and the possibility that the evolution of lactase has influenced some disease pattern distributions.

METHODS: A PubMed, Google Scholar and manual review of articles were used to provide a narrative review of the topic.

RESULTS: The concept of lactose intolerance is changing and merging with food intolerances. Microbial adaptation to regular lactose consumption in lactase-nonpersistent individuals is supported by limited evidence. There is evidence suggestive of a relationship among geographical distributions of latitude, sunhine exposure and lactase proportional distributions worldwide.

DISCUSSION: The definition of lactose intolerance has shifted away from association with lactose maldigestion. Lactose sensitivity is described equally in lactose digesters and maldigesters. The important medical consequence of withholding dairy foods could have a detrimental impact on several diseases; in addition, microbial adaptation in lactase-nonpersistent populations may alter risk for some diseases. There is suggestive evidence that the emergence of lactase persistence, together with human migrations before and after the emergence of lactase persistence, have impacted modern-day diseases.

CONCLUSIONS: Lactose maldigestion and lactose intolerance are not synonymous. Withholding dairy foods is a poor method to treat lactose intolerance. Further epidemiological work could shed light on the possible effects of microbial adaptation in lactose maldigesters. The evolutionary impact of lactase may be still ongoing.

\section{Key Words: Adaptation; Evolution; Intolerance; Lactose}

\section{La digestion du lactose chez les adultes et ses effets sur les maladies}

HISTORIQUE : L'assimilation du lactose par les adultes divise les humains en phénotypes lactase-persistant dominant et non persistant récessif.

OBJECTIFS : Examiner trois paramètres médicaux de la digestion du lactose, soit l'évolution du concept d'intolérance au lactose, les effets possibles de l'adaptation microbienne des populations lactase-non persistantes sur les maladies et la possibilité que l'évolution de la lactase ait eu une incidence sur des modèles de distribution pathologique.

MÉTHODOLOGIE : Les chercheurs ont effectué une analyse d'articles dans PubMed et Google Scholar et une analyse manuelle pour obtenir un examen narratif du sujet.

RÉSULTATS : Le concept d'intolérance au lactose évolue et fusionne avec les intolérances alimentaires. Peu de données probantes appuient le concept d'adaptation microbienne à la consommation régulière de lactose chez les personnes lactase-non persistantes. Des données probantes laissent supposer un lien entre la répartition géographique de latitude et d'exposition au soleil et la distribution proportionnelle de la lactase dans le monde.

EXPOSÉ : La définition d'intolérance au lactose s'est éloignée de la maldigestion du lactose. La sensibilité au lactose est décrite tout autant chez les personnes qui digèrent bien le lactose que chez celles qui le digèrent mal. L'évitement des produits laitiers pourrait contribuer à plusieurs maladies. De plus, l'adaptation microbienne des populations lactase-non persistantes pourrait modifier le risque lié à certaines maladies. Des données laissent supposer que l'émergence de persistance à la lactase, conjointement aux migrations humaines qui l'ont précédée et l'ont suivie, a eu un effet sur les maladies modernes.

CONCLUSIONS : Les termes maldigestion du lactose et intolérance au lactose ne sont pas synonymes. Il n'est pas conseillé d'éviter les produits laitiers pour traiter l'intolérance au lactose. D'autres recherches épidémiologiques pourraient jeter la lumière sur les effets possibles de l'adaptation microbienne des personnes qui digèrent mal le lactose. La lactase agit peutêtre encore sur l'évolution.
G enerally, humans are the only mammals who consume the milk of Other animals. Lactose in mother's milk is digested by infants of all human races and ethnic groups with the exception of a rare congenital absence of the intestinal enzyme lactase $(1,2)$. However, in adults, lactase (or lactase-phlorizin hydrolase) diminishes to approximately $10 \%$ of original levels in two-thirds to three-quarters of the human population (3). The loss of intestinal brush border lactase occurs in an inconsistent fashion (4), and begins at variable ages depending on race and ethnicity (3). Approximately 5\% of cow's milk consists of lactose.

The lactase gene (LCT) is found on chromosome $2 \mathrm{q} 21$ (5). Its transcription is controlled by a gene (MCM6) in cis position in exon 13, approximately $14 \mathrm{~kb}$ upstream from LCT. The ability in adults to digest lactose is a dominant trait known as lactase persistence (LP). Those who cannot digest lactose (recessive trait) are described as lactase nonpersistent (LNP) (3). The first gene identified to control transcription of lactase was described by Ennatah et al (6), who found the variant C/T-13910 approximately $14 \mathrm{~kb}$ away from LCT. In this polymorphism, substitution of thiamine for cytosine enables continued lactose digestion in adulthood. Another polymorphism G/A-22018A, was also described but is not as strongly associated with lactose digestion, at least in north Europeans (6). G/A-22018A is, however, the dominant control for lactase persistance in northern Chinese populations (7). Subsequently, several other polymorphisms were described in Africa $(8,9)$ and the Middle East (10).

The emergence of the ability to digest lactose is a relatively recent event in human history, occurring 7500 to 10,000 years ago (9). There are those who believe that lactase remains under evolutionary pressure (11). The emergence of LP divides the entire human population into those who can and those who cannot digest lactose in adulthood. Diseases affecting the brush border (eg, celiac disease, Giardia, bacterial overgrowth, viral gastroenteritis, radiation and others) can lead to secondary lactose maldigestion. Whether natural or as a result of small bowel disease, loss of intestinal lactase leads to a failure to split the disaccharide lactose into its monosaccharide components of glucose and galactose. As such, lactose reaches the colon and is then metabolized by intestinal bacteria.

There are two historical questions about the impact of lactose digestion/maldigestion on humans. First, is the teleological question 'why' some individuals develop LP status. The second is 'how' does the

Jewish General Hospital, Department of Medicine, Division of Gastroenterology, McGill University School of Medicine, Montreal, Quebec

Correspondence: Dr Andrew Szilagyi, Jewish General Hospital, Department of Medicine, Division of Gastroenterology, McGill University School of

Medicine, 3755 Cote St Catherine Road, E110, Montreal, Quebec H3T 1E2. Telephone 514-340-8144, fax 514-340-8282,

e-mail aszilagy@jgh.mcgill.ca

Received for publication August 12, 2014. Accepted December 16, 2014 
divide affect humans? The present narrative provides an overview of different levels at which dairy foods and milk consumption intersects with medical relevance.

\section{WHY IS THE WORLD'S POPULATION DIVIDED INTO TWO PHENOTYPES OF LACTOSE DIGESTION?}

Before the emergence of lactose digestion, all populations were believed to be LNP (12). More than 100,000 years ago, ancestors migrated from Africa into Europe and eastward into Russia, Siberia, India, China and the South Pacific. From Siberia during the last ice age, an existing land mass of Beringia allowed people to immigrate to the Americas $(13,14)$. Approximately 7500 to 10,000 years ago, lactose digestion emerged. There are several hypotheses as to why this occurred; however, two major ones dominate. In Europe, the calcium assimilation hypothesis is based on the observation that there is a steep north-south gradient in LP/LNP distributions with LNP increasing toward the south. Flatz and Rotthauwe (15) suggested that due to lack of sunshine and skin synthesis of vitamin D the ability to digest lactose allowed greater amounts of calcium assimilation from dairy foods, especially raw milk. This genetic advantage could reduce the prevalence of rickets. Around the same time frame, lactose digestion also emerged in Africa and the Middle East. However, the postulated environmental pressure was the practice of pastoralism and herding (16-18), which may also have allowed greater fluid ingestion in arid places such as desserts (18). The pastoral/herding model is referred to as the gene culture coevolution hypothesis. An analytical computer model of these two hypotheses provided evidence favouring the gene culture coevolution hypothesis over the calcium assimilation hypothesis. However, in Europe, the calcium assimilation model could not be excluded (19). The gene culture coevolution hypothesis in Europe suggests that LP dominance began in central Europe and populations then migrated both north and eastward. In more modern times, north and western European populations migrated into the new worlds of the Americas and Australia. Therefore, the modern day distributions of LP and LNP comprised predivide and postdivide human migrations with some intermingling of the two phenotypes.

\section{How does the dichotomy of lactose digestion impact humans?}

If we accept that the evolution of lactase persistence divides humans into two phenotypes with respect to dairy food and milk consumption, it is intuitive that these would have consequences. There are three broad areas in which the genetic divide could intersect with health issues. These include lactose intolerance, the effect of dairy food consumption on various diseases and the possible impact of the genetic evolution of LP status, together with pre- and posthuman migrations on the propensity for some diseases.

\section{Lactose intolerance}

The most clinically evident and researched effect is the concept of lactose intolerance. In the second half of the 20th century, when lactase was first described, it was hoped that a biochemical explanation for symptoms of irritable bowel syndrome (IBS) would be detected. In LNP individuals, ingestion of large quantities of lactose in a single session often induces cramps, abdominal bloating, flatus and, at times, diarrhea and even vomiting (20). The diagnosis of lactose maldigestion initially based on direct duodenal biopsies was too invasive. More practical indirect tests based on failure of rise of blood glucose (lactose tolerance test; measure of absorbed glucose) or a specific increase of measured breath hydrogen (measure of bacterial metabolism of maldigested lactose) after oral lactose loading are applied to clinical evaluation of lactose maldigestion. It is also used to evaluate lactose intolerance through various symptom scores at the time of testing (2123). These indirect tests have been validated against both intestinal biopsies $(24,25)$ as well as against (at least) the north European C/T-13910 polymorphism for lactase production (26).

Through extensive population-based studies, several findings are worth noting. Patients with IBS generally do not experience a higher frequency of lactose maldigestion than the background population
(27). The frequency of lactose intolerance, although most likely worse in lactose maldigestion individuals, is seen almost as frequently in LP populations $(27,28)$. These observations have led to a more recent concept of lactose sensitivity. This term refers to additional symptoms beyond the above outlined gastrointestinal symptoms (eg, headache, depression). Lactose sensitivity is increased but also becomes independent of race and ethnicity in patients with inflammatory bowel disease (IBD) $(29,30)$. Moreover, some of these persons meet criteria for IBS and also may have other carbohydrate sensitivities. This novel concept has been incorporated in the hypothesis and utilization of a multicarbohydrate-restrictive diet (Fermentable Oligo- Di- Monosaccharides and Polyols [FODMAP]) (31).

In LNP persons, the putative mechanisms of symptoms relate to osmotic accentuation of gastrointestinal motility and bacterial metabolism of maldigested lactose. A similar mechanism to LNP may affect LP persons with food sensitivities $(32,33)$. The long-term consequences of the FODMAP diet have yet to be elucidated, and shortterm use may be more suitable and easier to follow.

Nevertheless, the notion of the symptomatic consequences of lactose intolerance is a well-established obsession in the public view. This is reflected in the $>1$ million Internet searches regarding lactose intolerance. However, it has been shown in multiple studies that minute quantities of lactose in medication is imperceptible (34-36), small doses of lactose consumed (eg, $1 \mathrm{~g}, 9 \mathrm{~g}, 10 \mathrm{~g}$ ) are tolerated by most LNP persons (37), and double-blinded trials of lactose in one to two cups of milk per day separated in time are symptomatically indistinguishable by LNP persons $(38,39)$.

In individuals believing themselves to be lactose intolerant, minor psychological traits (eg, anxiety, depression and somatization) are prevalent. In addition, a nocebo effect for lactose (an expectation of adverse outcome with previous knowledge of the ingested substance) has been described $(32,36)$.

In fact, at an National Institutes of Health conference held in 2010, the main conclusions about the health effect of lactose intolerance was that the consequent avoidance of dairy foods, which could lead to several medical problems. Among these were most emphasized was the possibility of poor skeletal outcome with osteoporosis and fractures due to reduced calcium intake. There were also possibilities that dairy foods have a protective role for some features of the metabolic syndrome and several gastrointestinal cancers (notably colorectal cancer, but others as well) (40).

Treatments for lactose-intolerant individual include altered forms of dairy food ingestion (eg, yogurt, low-lactose cheeses). The use of lactose-reduced milk or extraneous lactase enzyme ingestion could also be helpful. A more recent method, not yet widely applied, is the use of intestinal microbial adaptation in lactose-intolerant persons who are also maldigesters $(41,42)$.

\section{EFFECT OF MILK AND DAIRY FOODS ON DISEASE}

The second effect of interest is the consumption of dairy foods and milk on different diseases. The LP/LNP divide has two different inherent characteristics that could influence disease risk. First, LNP populations consume lower quantities of milk (Figure 1) (43). This may be due to development of symptoms of lactose intolerance when larger quantities of lactose are consumed intermittently or may be cultural because the world's LNP populations live in Asia, Africa or Pacific locales. Second, when LNP persons do consume milk and lactose-containing dairy foods regularly over prolonged periods, bacterial adaptation occurs (41). This also has two consequences. Adapted LNP persons could consume more dairy foods without significant symptoms, and a modified colonic microflora over long periods may influence the development of various diseases. Adaptation to carbohydrates in LNP persons occurs via colonic bacterial modification. A formal description of this phenomenon was provided by Hertzler and Savaiano (41).

The definition includes altered bacterial response to lactose challenge with reduced hydrogen production after a period of regular lactose consumption and a variable reduction in aspects of lactose 


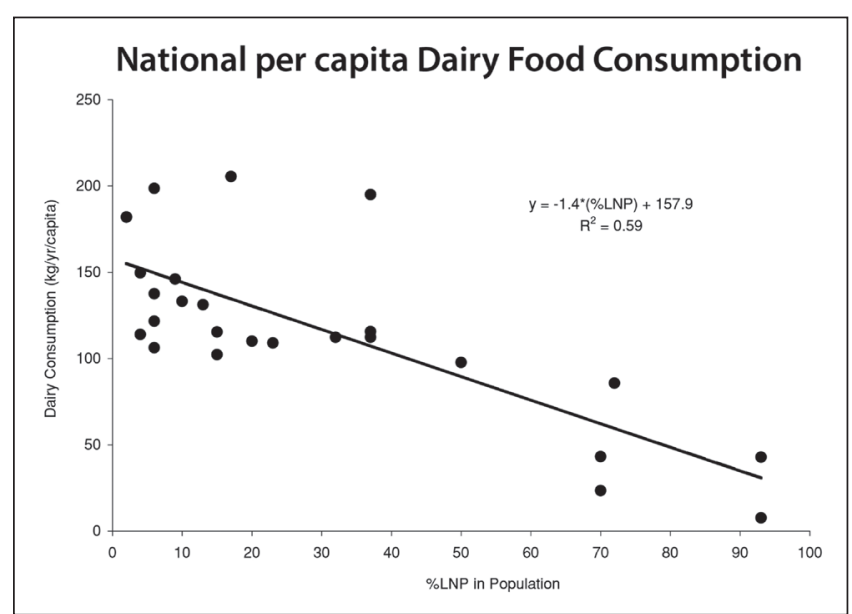

Figure 1) Dairy food consumption for is plotted against the percentage of the population in various countries that are lactase nompersistent (LNP). Twentyfive countries are represented and national total dairy food consumption was assessed up to March 2007. Reproduced with permission from Shrier et al (43)

intolerance symptoms. Other prebiotics derived from lactose are studied in an attempt to reduce symptoms by promoting colonic adaptation of lactose intolerance in LNP persons (42).

An equally important aspect supporting the existence of microfloral adaptation is the emergence of 'probiotic'-type bacteria in the colon, shown first in in vitro studies (44-46). There is also limited in vivo evidence for this (47), but the prebiotic effect of lactose is largely limited to LNP and not LP subjects $(48,49)$. The amount of lactose consumed at each meal plays a role in the spillover of lactose into the colon (50). It is not clear whether other mammals can also adapt in this manner because in adult humans at least, lactase is a nonadaptable enzyme to increased lactose ingestion (51). After cessation of lactose intake, de-adaptation is quite rapid after approximately two to three days (41). The altered microflora with increased lactic acid-producing types could lead to short-chain fatty acid production (52). The lactic acid and acetate, in turn, could promote other short-chain fatty acids, such as butyrate, through activation of butyrogenic bacteria (53). The dominant emerging species of bifidobacteria and lactobacilli, as well as other probiotics, have been studied for anticarcinogenic and immunemodifying effects (54).

These two additional characteristics, together with inherent active elements in milk and dairy foods (55), could independently or in concert modify dairy food impact on various diseases. The interactions are complex and there is a discrepancy between ecological and patient level-determined risk for disease. For example, on an ecological level, prostate and colorectal cancer, and ulcerative colitis rates are higher in populations consuming dairy foods, while those for stomach cancer are rates are lower (43).

In addition, ovarian, breast and lung cancers and Crohn disease (CD) appear to be under-represented in a significantly high proportion of LNP populations (43).

However, in patient-level studies, variable relationships emerge between dairy food and milk consumption and risk for these same diseases. The best example is the modest protective effect of dairy foods against colorectal cancer, contrary to ecologically defined expectations (56). In fact, dairy foods may protect against most gastrointestinal cancers (57). Although there are many active molecules in milk that could be anticarcinogenic (58), the putative protection against colorectal cancer is through calcium (59). At least in Western societies, the addition of vitamin $\mathrm{D}$ is also believed to be protective (60). When studies from different geographical locales in the world are grouped into relative high, low or mixed proportions of LP/LNP distributions, however, dairy foods and milk provide statistically significant reduced relative rates only in high and low LP/LNP (Figure 2) (56). The high

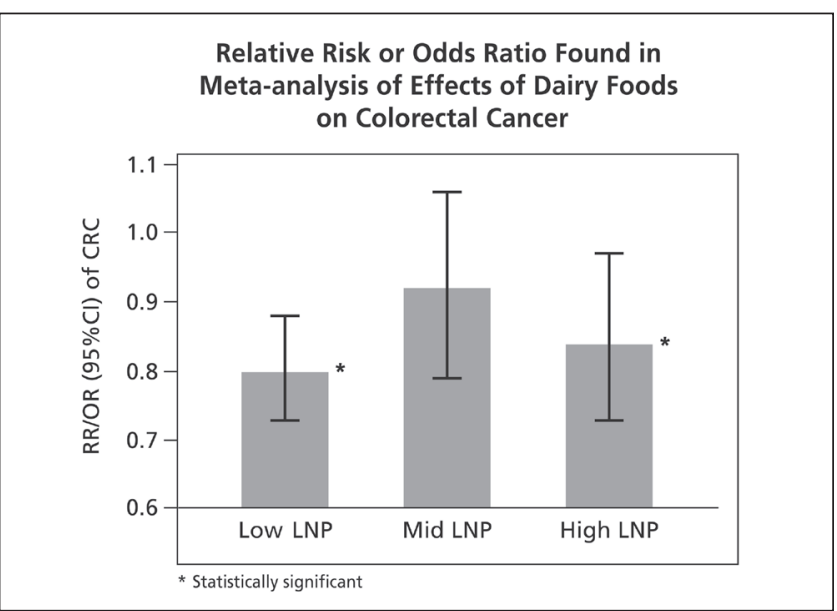

Figure 2) Summary of relative risks of the effects of dairy food consumption on colorectal cancer (CRC) are shown with $95 \%$ CIs presented as bar graphs from three geographical areas of the world divided into groups of countries with high $(\geq 80 \%)$, low ( $\leq 20 \%$ ) and mid (average 50\% [21\% to 79\%]) lactase-nonpersistent (LNP) proportions of the population. Modest reduction of $\mathrm{CRC}$ rates are found in both high and low LNP countries. In studies using data from intermediate LNP countries, the effects of dairy foods on CRC are diminished and are not statistically significant. The graph is based on meta-analyses of relevant studies from 1975 to 2005. Modified from Szilagyi et al (56) with permission

dairy food-related intake of calcium is not achieved in LNP populations as proposed in high LP populations. Also, at the time of the analyses, vitamin D was not added to milk in most high-proportion LNP populations. This study supports a hypothetical role for colonic adaptation to lactose as a possible additional active anticarcinogenic agent through manipulation of the microbiome.

In the case of other various gastrointestinal cancers, however, mechanisms of apparent protection may be different and the role of prebiotics is even less clear. Furthermore, adapted LNP individuals could consume higher quantities of dairy foods and face exposure to other active elements.

Other cancers also have controversial relationships with dairy food consumption. Of these, prostate cancer has been more aligned with a detrimental effect, possibly through the injurious impact of calcium (61-63). It is of interest that, despite an increased intake of dairy foods in individuals with dominant TT genotype for lactase compared with CT or the CC recessive genotype, there was no relationship to prostate cancer (64). However, when phenotype of lactose intolerance was examined, there were fewer LNP individuals in a group with prostate cancer (65).

The deleterious effect of dairy foods on testicular cancer has been reported $(66,67)$; however, a risk-reductive effect on bladder cancer, which may be more evident in Asians, has also been noted (68). Probiotics have shown some protection against bladder cancer $(69,70)$, suggesting that a lactose prebiotic effect may have been responsible for the observed differences between Europeans and Asians.

Originally, Cramer (71) postulated that because rates of ovarian cancer were low in populations with high proportion of LNP individuals, galactose in LP individuals could be toxic to the ovaries. However, the notion that dairy food consumption increases the risk of ovarian cancer has been highly controversial and, currently, the role of galactose has not been shown (72-77).

Breast cancer, which is more common in high dairy-consuming nations, has a variable relationship to milk and dairy food consumption. Initial data suggested increased risk with high fat and presence of estrogen compounds in milk cows (78). More recent studies were unable to confirm risk and suggested even protection by low-fat dairy foods $(79,80)$. The relationship between milk consumption and lung cancer has not been established (81). 
TABLE 1

\section{Hypothesized effects of dairy food consumption on various diseases}

\begin{tabular}{|c|c|c|}
\hline Promotes & Protects & Independent \\
\hline Prostate cancer* $(61-65)$ & Colorectal cancer $^{*}(56,57)$ & Breast cancer* (78-80) \\
\hline Ovarian cancer* $(71-77)$ & Bladder cancer (68) & Lung cancer* $(81)$ \\
\hline Testicular cancer $(66,67)$ & Stomach cancer ${ }^{\dagger}(57)$ & Crohn disease ${ }^{*}(88-90)$ \\
\hline Ulcerative colitis* $(86,87)$ & Osteoporosis $(83,84)$ & Atherosclerosis (98-100) \\
\hline \multirow[t]{3}{*}{ Cataracts (96) } & Obesity $(93,94)$ & \\
\hline & Hypertension (97) & \\
\hline & Type II diabetes (95) & \\
\hline
\end{tabular}

*More common in lactase-persistent societies; ${ }^{+}$More common in lactasenonpersistent societies (43). The other diseases are believed to be more common in 'Western' societies. The list is based on patient level studies and most are based on meta-analyses or large single reports. Given the variability of studies and meta-analytical outcomes, these relationships are estimates and do change. For example, there are studies that suggest that low-fat dairy foods may protect against breast cancer (80). Similarly, unpasteurized milk may protect against Crohn disease (90)

Among other non-neoplastic diseases, IBD (CD and idiopathic ulcerative colitis [UC]) is more common in high dairy food-and milkconsuming nations, although only UC reaches a statistically significant level. High-proportion LNP nations tended to have lower IBD rates (43). On the patient level, the results from different studies do not specifically implicate dairy products $(82)$, although low calcium and low vitamin D are risks for osteopenia $(83,84)$, and associated with increased risk for colorectal cancer (85). There are fewer cohort studies examining the impact of dairy food consumption on IBD. Existing reports are conflicting. A study from Japan epidemiologically links a number of 'Western' foods, including dairy products, with the emergence of IBD in that country (86). An earlier study from France examined 'harmful' foods (including dairy products) that were excluded from diet of patients with IBD (87). The increased prevalence of lactose intolerance and sensitivity in CD was noted above (30). However, other studies did not find dairy foods to be associated with development or aggravation of IBD $(88,89)$, and at least one study found pasteurized milk to be protective for CD (90). The north European lactase genetic polymorphism correlation with IBD has been evaluated in very few studies. A German study failed to find any increased rates of IBD in CC or GG genotypes evaluated in patients and controls (91). However, the TT dominant genotype was found to be related to CD risk in Caucasians from New Zealand (92).

Several other non-neoplastic diseases, such as obesity $(93,94)$, the metabolic syndrome (95) and cataracts (96), and cardiovascular disorders such as hypertension (97) and atherosclerosis (98-100), have been evaluated for a relationship with milk and dairy food consumption. Results generally have also been controversial. Table 1 outlines the relationships of diseases with dairy food consumption.

Although the effects of consumption of dairy foods on various diseases have been described, there is no clear outcome for most. Gastrointestinal cancers, especially colon cancer, appear to derive benefit from dairy products, but prostate and ovarian cancer appear to have increased risk. The failure to show conclusive outcomes are due to several factors, including variations in data-collection methods, variation in populations, and focus variability in studies (eg, different foods versus dairy products and their derivatives), all of which are likely to play a role in accounting for different outcomes. The specific elements in dairy products and milk, which potentially affect each disease, may also vary. The question from the perspective of the present review is whether ignoring differences between LP and LNP individuals may play a role in outcome of studies?

Potential impact of the role of dosage or a threshold effect of putative pathogenic elements in dairy foods may depend on LP or LNP status. In the genetic relationship between lactase and prostate cancer (64), there was a quantitative difference in dairy food intake among the three haplotypes, but a discrepancy in prostate cancer prevalence. In these cases, CC genotypes consume the least and TT the most dairy products; however, total intakes of these products were not incorporated in the analysis. In this regard, studies of diseases (not putatively affected by microbial flora) may incorporate adapted LNP patients able to consume more dairy foods.

In diseases in which microbial flora are relevant to pathogenesis, adapted LNP persons may be protected compared with LP and unadapted LNP persons. These aspects have not been adequately evaluated in relation to disease.

The possible impact of LP evolution on disease development The third and most intriguing impact of the lactase dichotomy on diseases may be related to the emergence of LP status 7500 to 10,000 years ago. Timing of population migration (ie, before and after the emergence of LP) reflect modern day lactase distributions of populations.

An interesting observation was reported in 1980 by Garland and Garland (101), who suggested that latitude - specifically, increased vitamin D skin synthesis through greater exposure to sunlight reduced mortality of colon cancer. Subsequently, at least 23 cancers and other diseases were noted to have reduced risk toward the equator (102-104). In addition, reports accumulated on the antineoplastic and immunomodulating effects of vitamin D $(105,106)$, and beneficial effects of vitamin $\mathrm{D}$ were described in other cancers and autoimmune diseases.

In parallel with the sunshine hypothesis, a few groups also linked reduced disease risk with increasing proportions of LNP status of the populations $(13,71,107,108)$. These reports, however, were largely overshadowed by the importance attributed to modifying effects of vitamin D. Later, seven 'Western' lifestyle diseases were confirmed to negatively relate with increasing population LNP frequency (43). The direction of disease risk reduction mimicked that observed with diminishing latitude and increasing sunshine exposure. The relationship of these two variables raised the question as to why this should be so. Did sunshine exposure play a role in evolution of LP status? As outlined above, in Europe, such a relationship could not be entirely excluded (17); however, a parallel evolution of LP in a spotty fashion in Africa supports pastoralism and animal husbandry as the dominant environmental pressure for the event (109). Nevertheless LP/LNP northsouth gradients do exist at a much reduced level in Africa (17), and also in India (110) and China (7). However, this process, at least in Asia, is attributed mostly to population migrations after the emergence of LP, rather than to de novo evolution $(111,112)$. Similarly, LP migrations to the new worlds of the Americas and Australia took place long after LP emergence in Europe. In this paradigm, latitude and sunshine are relatively fixed variables and LP/LNP distributions change overtime as further migrations of LNP populations occur in the current and last centuries.

Diseases also change over time due to altered environment and altered host susceptibility. It is interesting that many modern diseases (increases in the past 50 years) appear to originate and be prevalent in 'Western' societies. These include cancers, autoimmune diseases and those affiliated with the metabolic syndrome. These 'Western' lifestyle hypothesized diseases are also increasing in areas with previously low rates which are becoming more industrialized. The changing lifestyles support 'Western' lifestyle-associated environment changes in pathogenesis of these diseases.

Nevertheless, the apparent interactions of latitude, sunshine and LP/LNP distributions suggest mechanisms that may act together or independently to describe particular geographical patterns of disease. Sunshine putatively acts largely through vitamin D, which impacts many diseases through immune and neoplastic interventions. The role of LP/LNP is likely different and more complex.

$\mathrm{CD}$ and UC offer a model to study relationships between the two worldwide disease-modifying risk variables. There are a number of features of IBD that qualifies it as a worthy model, reflecting possible interactions. 
IBD became an important disease in the past 75 years and rates are increasing in Westernized societies. Also, IBD has been linked both with sunshine (113), vitamin D (114) and lactase distributions $(43,108)$. In general, UC precedes CD by approximately 15 to 20 years (115)

IBD is currently attributed to an interaction between genetic susceptibility, altered intestinal microflora and disturbance in control of the immune response (116). There are currently 163 genes attributed to susceptibility or protection against either of the main forms of IBD, with approximately two-thirds interacting with both diseases (117). Furthermore genetic polymorphisms associated with IBD have also been linked to some 24 other diseases, many of which are autoimmune mediated but others are not (eg, colorectal cancer) (118).

Finally, in the past two to four years, substantial new information emerged both on world distributions of LP/LNP (119) and the incidence rates of IBD (120).

An epidemiological re-evaluation of the relationships of both forms of IBD with latitude, sunshine and LP/LNP distributions revealed that modest to moderate correlations with all three variables can be found over a 30-year period (median year 2000) (121). This study suggested that LNP and high sunshine exposure appear to reduce risk of disease worldwide. When analysis is divided separately into European and non-European theatres, it becomes clear that global effects are largely driven by correlations in Europe. However, in nonEuropean locations, the correlations with latitude and sunshine are somewhat weaker and LNP status has a greater risk-reducing effect. Because both national IBD rates and LP/LNP distributions were largely estimated, the actual magnitude of effect sizes are less reliable. However, it is argued that independent regional data on rates of the two changing variables (IBD and lactase) were published without bias of expected correlations by multiple authors. Second, even if average national values were obtained for large countries in North America and Asia, there is no dispute that LP frequency dominates in the former and LNP in the latter. This observation gives lateral polarity (a global west to east gradient from North America to east) to any possible effect of LP/LNP status. It is thus argued that any relationship that significantly correlates disease rate with LP/LNP status echoes a potential influence of the event that occurred millennia ago.

The relationship of IBD to both sunshine and LP/LNP distributions suggests there may indeed be interactions between these two variables. Even if sunshine has a role in evolution of LP status, the mechanism of effect of lactase distributions on diseases would be expected to differ from that of sunshine and vitamin D and is likely to be complex. One of the most likely influences of lactase evolution is the co-evolution of other genes that could contribute to other diseases. There are a number of these hypothesized.

The human leukocyte antigen system for immunity has been correlated with dominant lactase frequency in Europe (17). It is postulated that the nuclear oligomerization domain (NOD2) system evolved together with lactase dominance, also in Europe. This system is involved in preventing bacteria associated with unpasteurized milk drinking from invading the host. These bacteria included Mycobacterium bovis, Listeria, Escherichia coli and others $(122,123)$.

The cystic fibrosis sodium transport receptor may also have evolved in Europe (124-126). It is postulated that the heterozygous mutation of this polymorphism may have protected against diarrhea caused by agents incurred by milk drinking.

Other genetic polymorphisms have also been hypothesized to have coevolved with lactase $(127,128)$. The generalizability of the IBD model to show an evolutionary role of lactase in shaping of modernday 'Western' diseases is unproven. However, the described similarities in risk reduction for several other diseases by both sunshine exposure and increasing LNP proportion of the population does suggest that these observations are not merely coincidental.

Mechanisms other than direct genetic alterations involve the vastly different environment in low-latitude countries where infectious diseases still impact dominant disease profiles. Other differences may be economic and relate to gross national products as well as distribution of wealth in the country. This latter mechanism would impact on access to health care by the local populations, perhaps resulting in under-reporting or under-recognition of various diseases.

\section{SUMMARY AND CONCLUSIONS}

In the present review, three interconnected effects of the dichotomous phenotypic division of humans into lactose digesters and maldigesters were emphasized.

To date, the major focus of research on human health has been the effect of lactose intolerance. In this context, there are two paradigm shifts. First, the definition of lactose intolerance has been broadened. It is no longer acceptable to interchange the terms lactose intolerance and lactose maldigestion. Malabsorption may be secondary to intestinal diseases but the large majority of the world is genetically divided in adulthood into LP and LNP populations. While lactose intolerance still occurs in LNP, care must be taken to determine whether symptoms occur during testing only, whether symptoms are self-reported without testing or whether symptoms are independent of lactose maldigestion status. In this latter category, lactose intolerance may be part of the broader concept of food sensitivities that can affect LP and LNP approximately equally. Second, with the shift in definitions, the greater medical issue is the failure to consume dairy products, which could lead to medical problems as outlined at a National Institutes of Health conference on lactose intolerance (40).

The second medical issue, which generally has not been emphasized, is the possible impact of the different ways that LP and LNP handle consumption of dairy products. These interactions are likely complex because of the multiple active elements in milk and different influence on possible disease pathogenesis. In general, diseases that would be affected by larger intakes of dairy foods (and in which the putative pathogenic factor is not lactose) could also impact adapted LNP persons who are now able to consume larger quantities of dairy products (eg, diseases such as prostate and testicular cancer). However, diseases in which a favourably modified intestinal flora may act against the disease, dairy food and/or milk-consuming LNP persons may be somewhat protected (eg, diseases such as colorectal cancer and bladder cancer).

It would be of interest to evaluate dairy foods from this perspective because consumption of lactose by LNP in the modern world may represent one of the largest natural use of a prebiotic that can be quantified. In the wake of important population differences in the microbiome and pattern differences among several human diseases (129-131), the impact of dairy food consumption on microbial flora between LP and LNP may be of further interest.

Third, the relationship among latitude, sunshine and LP/LNP distributions explains the observation that low latitude, high sunshine exposure and increasing LNP population proportions mimic similar apparent disease rate reductions. However, the relationship of these two different variables makes it highly unlikely that the evolution of LP status effect is coincidental. The relationship with lactase is likely to be quite complex.

The possibility that the evolution of dominant lactase persistence appears to provide a background for the geographic spread of 'Western' lifestyle diseases is intriguing. The ability to digest lactose generally is believed to have arisen as a need to improve nutrition in populations that have adopted a pastoral life style, or to protect against bone disease (in Europe). The co-evolution of other genes to accommodate the new source of nutrition likely accompanied this great divide. In modern times, the changing industrialized lifestyles, along with changes in diet, likely impact on existent genes through alterations of the colonic microenvironment leading to development of neoplastic and immune-mediated diseases. Some of these questions are outlined in Table 2. 
TABLE 2

\section{Remaining questions concerning lactose, lactase and disease interactions}

Because bacterial metabolism is postulated to be associated with both bacterial and immunological response to maldigested lactose in intolerant lactose maldigesters, what is the mechanism of lactose sensitivity in lactose digesters?

Because colonic bacterial adaptation is a real phenomenon in lactose maldigesters consuming regular dairy foods, does such a potential prebiotic effect influence host health over the long term?

Is there a real impact of lactase status on outcome of studies examining effects of dairy foods on different diseases, given the outlined difference of handling dairy food consumption by lactase-persistent compared with lactase-nonpersistent populations?

Is the inflammatory bowel disease model representative of a possible genetic evolutionary mechanism that responds to current dietetic environmental pressures predisposing to some diseases?

Given modern-day migrations of lactase-nonpersistent populations, dominance of the lactase persistent genotype and changing progressive 'Western' type diet, should we expect further evolutionary changes accompanying these environmental pressures?

ACKNOWLEDGEMENT: This review was funded by a general academic grant from the Department of Medicine of the Jewish General Hospital, Montreal, Quebec.

\section{REFERENCES}

1. Saviahti A, Launiala K, Kuitunen P. Congenital lactase deficiency. A clinical study on 16 patients. Arch Dis Child 1983;58:246-52.

2. Uchida N, Sakamoto O, Irie M, et al. Two novel mutations in the lactase gene in a Japanese infant with congenital lactase deficiency. Tohoku J Exp Med 2012;227:69-72.

3. Swallow DM. Genetics of lactase persistence and lactose intolerance. Ann Hum Genet 2003;37:197-219.

4. Maiuri L, Raia V, Potter J, et al. Mosaic pattern of lactase expression by villous enterocytes in human adult-type hypolactasia. Gastroenterology 1991;100:359-69.

5. KruseTA, Bolund L, Grzeschik KH, et al. The human lactase-phlorizin gene is located on chromosome 2. FEBS Lett 1988;240:123-6.

6. Enattah NS, Sahi T, Savilahti E, Terwilliger JD, Peltonen L, Järvelä I. Identification of a variant associated with adult-type hypolactasia. Nat Genet 2002;30:233-7.

7. Xu L, Sun H, Zhang X, et al. The G-22018 A allele matches the lactase persistence phenotype in northern Chinese populations. Scand J Gastroenterol 2010;45:168-74.

8. Ingram CJE, Elamin MF, Mulcare CA, et al. A novel polymorphism associated with lactose tolerance in Africa: Multiple causes for lactase persistence? Hum Genet 2007;120:779-88.

9. Tishkoff SA, Reed FA, Ranciaro A, et al. Convergent adaptation of human lactase persistence in Africa and Europe. Nat Genet 2007;39:31-40.

10. Imtiaz F, Savilahti E, Sarnesto A, et al.The T/G 13915 variant upstream of the lactase gene (LCT) is the founder allele of lactase persistence in an urban Saudi population. J Med Genet 2007;44:4e89.

11. Bersaglieri T, Sabeti PC, Patterson N, et al. Genetic signatures of strong recent positive selection at the lactase gene. Am J Hum Genet 2004;74:1111-20.

12. Burger J, Kirchner M, Bramanti B, Haak W, Thomas MG. Absence of the lactase-persistence-associated allele in early Neolithic Europeans. Proc Natl Acad Sci USA. 2007;104: 3736-41.

13. Forster P, Matsumura S. Did early humans go north or south. Science 2005;308:965-6.

14. Malyarchuk B, Derenko M, Denisova G, et al. Ancient links between Siberians and native Americans revealed by subtyping the Y chromosome haplogroup Q1A. J Hum Genet 2011;56:583-8.

15. Flatz G, Rotthauwe HW. Lactose nutrition and natural selection. Lancet 1973;2:76-7.

16. Simoons FJ. Primary adult lactose intolerance and the milking habit: a problem in biologic and cultural interrelations. II: A culture historical hypothesis. Am J Dig Dis 1970;15:695-710.
17. Simoons FJ. The geographic hypothesis and lactose malabsorption: A weighing of the evidence. Am J Dig Dis 1978;23:963-80.

18. Holden C, Mace R. Phylogenetic analysis of the evolution of lactose digestion in adults. Hum Biol 1997;69:605-28.

19. Gerbault P, Moret C, Currat M, Sanchez-Mazas A. Impact of selection and demography on the diffusion of lactase persistence. PLoS One, 2009;4:e6369doi:10.1371/journal.pone.0006369. 20. Misselwitz B, Pohl D, Fruhauf H, Fried M, Vavricka S, Fox M. Lactose malabsorpyion and intolerance: Pathogenesis, diagnosis and treatment. United Eur Gastroenterol J 2013;1:151-9.

21. Newcomer AD, McGill DB, Thomas PJ, Hofmann AF. Prospective comparison of indirect methods for detecting lactase deficiency. N Engl J Med 1975;293:1232-6.

22. Arola H. Diagnosis of hypolactasia and lactose malabsorption. Scand J Gastroeneterol 1994;202:26-35.

23. Waud JP, Matthews SB, Campbell AK. Measurement of breath hydrogen and methane, together with lactase genotype, defines the current best practice for investigation of lactose sensitivity. Ann Clin Biochem 2008;45(Pt 1):50-8.

24. Furnari M, Bonfanti D, Parodi A, et al. A comparison between lactose breath test and quick test on duodenal biopsies for diagnosing lactase deficiency in patients with self- reported lactose intolerance. J Clin Gastroenterol 2013;47:148-52.

25. Enattah NS, Kuokkanen M, Forsblom C, et al. Correlation of intestinal disaccharidase activities with the C/T-13910 variant and age. World J Gastroenterol 2007;13:3508-12.

26. Marton A, Xue X, Szilagyi A. Meta-analysis: The diagnostic accuracy of lactose breath hydrogen or lactose tolerance tests for predicting the north European lactase polymorphism C/T - 13910. Aliment Pharmacol Ther 2012;35:429-40.

27. Farup PG, Monsbakken KW, Vandvik PO. Lactose malabsorption in a population with irritable bowel syndrome: Prevalence and symptoms. A case-control study. Scand J Gastroenterol 2004;7:645-9.

28. Szilagyi A, Malolepszy P, Yesovitch S, et al. Inverse dose effect of pretest dietary lactose intake on breath hydrogen results and symptoms in lactase non persistent subjects. Dig Dis Sci 2005;50:2178-82.

29. Mishkin S. Dairy sensitivity, lactose malabsorption, and elimination diets in inflammatory bowel disease. Am J Clin Nutr 1997;65:564-7.

30. Eadala P, Mathews SB, Waud JP, Gren JT, Campbell AK. Association of lactose sensitivity with inflammatory bowel disease demonstrated by analysis of genetic polymorphism, breath gases and symptoms. Aliment Pharmacol Ther 2011;34:735-46.

31. Gibson PR, Shepherd SJ. Personal view: Food for thought Western lifestyle and susceptibility to Crohn's disease. The FODMAP hypothesis. Aliment Pharmacol Ther 2005;21:1399-409.

32. Yang J, Fox M, Cong Y, et al. Lactose intolerance in irritable bowel syndrome patients with diarrhea: The roles of anxiety, activation of the innate mucosal system and visceral sensitivity. Aliment Pharmacol Ther 2014;39:302-11.

33. Gibson PR Shepherd SJ. Evidence-based dietary management of functional gastrointestinal symptoms: The FODMAP approach. J Gastroenterol Hepatol 2010;25:252-8.

34. Montalto M, Gallo L, Santoro L, et al. Low-dose lactose in drugs neither increases breath hydrogen excretion nor causes gastrointestinal symptoms. Aliment Pharmacol Ther 2008;28:1003-12.

35. Casellas F, Aparici A, Casaus M, Rodríguez P, Malagelada JR.Subjective perception of lactose intolerance does not always indicate lactose malabsorption. Clin Gastroenterol Hepatol 2010;8:581-6.

36. Tomba C, Baldassarri A, Coletta M, Cesana BM, Basilisco G. Is the subjective perception of lactose intolerance influenced by the psychological profile? Aliment Pharmacol Ther 2012;36:660-9.

37. Hertzler SR, Huynh BC, Savaiano DA. How much lactose is low lactose. J Am Diet Assoc 1996;96:243-6.

38. Suarez FL, Savaiano DA, Levitt MD. A comparison after the consumption of milk or lactose-hydrolyzed milk by people with self-reported severe lactose intolerance. N Engl J Med 1995;333:1-4.

39. Suarez FL, Savaiano D, Arbisi P, Levitt MD. Tolerance to the daily ingestion of two cups of milk by individuals claiming lactose intolerance. Am J Clin Nutr 1997;65:1502-6.

40. Suchy FJ, Brannon PM, Carpenter TO, et al. National institute of health consensus development conference: Lactose intolerance in health. Ann Intern Med 2010;152:792-6. 
41. Hertzler SR, Savaiano DA. Colonic adaptation to daily lactose feeding in lactose maldigesters reduces lactose intolerance. Am J Clin Nutr 1996;64:232-6.

42. Savaiano DA, Ritter A, Klaenhammer TR, et al. Improving lactose digestion and symptoms of lactose intolerance with a novel galactooligosaccharide (RP-G28): A randomized, double-blind clinical trial. Nutr J 2013;12:160-9.

43. Shrier I, Szilagyi A, Correa JA. Impact of lactose containing foods and the genetics of lactase on diseases: An analytical review of population data. Nutr Cancer 2008;60:292-300.

44. Jiang, T; Savaiano, DA. In vitro lactose fermentation by human colonic bacteria is modified by Lactobacillus acidophilus supplementation. J Nutr 1997;1237:1489-95.

45. Jiang T, Savaiano DA. Modification of colonic fermentation by bifidobacteria and $\mathrm{pH}$ in vitro. Impact on lactose metabolism, short-chain fatty acid, and lactate production. Dig Dis Sci 1997;42:2370-7.

46. Makivuokko HA, Saarinen MT, Ouwehand AC, Rautonen NE. Effects of lactose on colon microbial community structure and function in a four-stage semi-continuous culture system. Biosci Biotechno Biochem 2006;70:2056-63.

47. Ito M, Kimura M. Influence of lactose on faecal microflora in lactose maldigesters. Microb Ecol Health Dis 1993;6:73-6.

48. Szilagyi A. Review article: Lactose - a potential prebiotic. Aliment Pharmacol Ther 2002;16:1591-602.

49. Szilagyi A, Shrier I, Heilpern D, et al. Differential impact of lactose/ lactase phenotype on colonic microflora. Can J Gastroenterol 2010;24:373-9.

50. Oku T, Nakamura S, Ichinose M. Maximum permissive dose of lactose and lactitol for transitory diarrhea, and utilizable capacity for lactose in Japanese female adults. J Nutr Sci Vitaminol 2005;51:51-7.

51. Gilat T, Russo S, Gelman-Malachi E, Aldor TA. Lactase in man: A nonadaptable enzyme. Gastroenterology 1972;62:1125-7.

52. He T, Venema K, Priebe MG, Welling GW, Brummer R.-J, Vonk RJ. The role of colonic metabolism in lactose intolerance. Eur J Clinical Invest 2008;38:541-7.

53. Duncan SH, Louis P, Flint HJ. Lactate-utilizing bacteria, isolated from human feces, that produce butyrate as a major fermentation product. Appl Environ Microbiol 2004;70:5810-7.

54. Commane D, Hughes R, Short C, Rowland I. The potential mechanisms involved in the anti-carcinogenic action of probiotics. Mut Res 2005;591:276-89.

55. Severin S, Wenshui X. Milk biologically active components as nutraceuticals. Rev Crit Rev Food Sci Nutr 2005;45:645-56.

56. Szilagyi A, Nathwani U, Vinokuroff C, Correa JA, Shier I. Evaluation of relationships among national colorectal cancer mortality rates, genetic lactase non persistence status and per capita yearly milk and milk product consumption. Nut Cancer 2006;55:151-6.

57. Park Y, Leitzmann MF, Subar, et al. Dairy food, calcium, and risk of cancer in the NIH-AARP diet and health study. Arch Intern Med 2009;169:391-401.

58. Norat T, Riboli E. Dairy products and colorectal cancer: A review of possible mechanisms and epidemiological evidence. Eur J Clin Nutr 2003;57:1-17

59. Grau MV, Baron JA, Sandler RS, et al. Prolonged effect of calcium supplementation on risk of colorectal adenomas in a randomized trial. J Natl Cancer Inst 2007;99:129-36.

60. Grau MV, Baron JA, Sandler RS, et al. Vitamin D, calcium supplementation, and colorectal adenomas: Results of a randomized trial. J Natl Cancer Inst 2003;95:1765-71.

61. Torfadottir JE, Steingrimsdottir L, Mucci L, et al. Milk intake in early life and risk of advanced prostate cancer. Am J Epidemiol 2012;175:144-53.

62. Pettersson A, Kasperzyk JL, Kenfield SA, et al. Milk and dairy consumption among men with prostate cancer and risk of metastases and prostate cancer death. Cancer Epidemiol Biomarkers Prev 2012;21:428-36.

63. Song Y, Chavarro JE, Cao Y, et al. Whole milk intake is associated with prostate cancer-specific mortality among U.S. male physicians. J Nutr 2013;143:189-96.

64. Travis RC, Appleby PN, Siddiq A, et al. Genetic variation in lactase gene, dairy product intake and risk for prostate cancer in the European prospective investigation into cancer and nutrition. Int J Cancer 2013;132:1901-10.
65. Agarwal MM, Rana SV, Mandal AK, et al. Lactose intolerance in prostate cancer patients: Incidence and associated factors. Scand J Gastroeneterol 2008;43:270-6.

66. Davies TW, Palmer, CR, Lipscombe JM. Adolescent milk, dairy product and fruit consumption and testicular cancer. Br J Cancer 1998;74:657-60.

67. Stang A, Ahrens W, Baumgrdt-Elms C. Adolescent milk fat and galactose consumption and testicular cell cancer. Cancer Epidemiol Biomark Prev 2006;15:2189-95.

68. Mao QQ, Dai Y, Lin YW, Qin J, Xie LP, Zheng XY. Milk consumption and bladder cancer risk: Meta-analysis of published epidemiological studies. Nut Cancer 2011;63:1263-71.

69. Hayatsu H, Hayatsu T. Suppressing effect of Lactobacillus casei administration on the urinary mutagenicity arising from ingestion of fried ground beef in the human. Cancer Lett 1993; $73: 173-9$

70. Aso Y, Akaza H, Kotake T, Tsukamoto T, Imai K, Naito S. Preventive effect of a Lactobacillus casei preparation on the recurrence of superficial bladder cancer in a double-blind trial. The BLP study group. Eur Urol 1995;27:104-9.

71. Cramer DW. Lactase persistence and milk consumption as determinants of ovarian cancer risk. Am J Epidemiol 1989;130:904-10.

72. Qin LQ, Xu JY, Wang PY, et al. Milk/dairy products consumption, galactose metabolism and ovarian cancer: Meta-analysis of epidemiological studies. Eur J Cancer Prev 2005;14:13-9.

73. Larsson SC, Orsini N, Wolk A. Milk, milk products and lactose intake and ovarian cancer risk: A meta-analysis of epidemiological studies. Int J Cancer 2006;118:431-41.

74. Genkinger JM, Hunter, DJ, Spiegelman D, et al. Dairy products and ovarian cancer: A pooled analysis of 12 cohort studies. Cancer Epidemiol Biomarkers Prev 2006;15:364-72.

75. Faber MT, Jensen A, Søgaard M, et al. Use of dairy products, lactose, and calcium and risk of ovarian cancer - results from a Danish case-control study. Acta Oncol 2012;51:454-64.

76. Mommers M, Schouten LJ, Goldbohm RA, van den Brandt PA Dairy consumption and ovarian cancer risk in the Netherlands Cohort Study on Diet and Cancer. Br J Cancer 2006;94:165-70.

77. Schulz M, Nöthlings U, Allen N, et al. No association of consumption of animal foods with risk of ovarian cancer. Cancer Epidemiol Biomark Prev 2007;16:852-5.

78. Ganmaa D, Sato A. The possible role of female sex hormones in milk from pregnant cows in the development of breast, ovarian and corpus uteri cancers. Med Hypotheses 2005;65:1028-37.

79. Krog V, Berrino F, Sieri S, et al. Meat, eggs, dairy products, and risk of breast cancer in the European Prospective Investigation into Cancer and Nutrition (EPIC) cohort. Am J Clin Nutr 2009;90:602-12.

80. Dong JY, Zhang L, He K, Qin LQ. Dairy consumption and risk of breast cancer: A meta-analysis of prospective cohort studies. Breast Cancer Res Treat 2011;127:23-31.

81. Sankaranarayanan R, Varghese C, Duffy SW, Padmakumary G, Day NE, Nair MK. A case-control study of diet and lung cancer in Kerala, south India. Int J Cancer 1994;58:644-9.

82. Richman E, Rhodes JM. Review article: Evidence-based dietary advice for patients with inflammatory bowel disease. Aliment Pharmacol Ther 2013;38:1156-71.

83. Vernia P, Loizos P, Di Giuseppantonio I, Amore B, Chiappini A, Cannizzaro S. Dietary calcium intake in patients with inflammatory bowel disease. J Crohn's Colitis 2014;8:312-7.

84. Ghishan FK, Kiela PR. Advances in the understanding of mineral and bone metabolism in inflammatory bowel diseases. Am J Physiol Gastrointest Liver Physiol 2011;300:G191-201.

85. Ananthakrishnan AN, Cheng SC, Cai T, et al. Association between reduced plasma 25-hydroxy vitamin D and increased risk of cancer in patients with inflammatoy bowel diseases. Clin Gastoenterol Hepatol 2014;12:821-7.

86. Asakura H, Suzuki K, Kitahora T, Morizane T. Is there a link between food and intestinal microbes and the occurrence of Crohn's disease an ulcerative colitis. J Gastroenterol Hepatol 2008;23:1794-801.

87. Joachim G. The relationship between habits of food consumption and reported reactions to food in people with inflammatory bowel disease - testing the limits. Nutr Health 1999;13:69-83.

88. Gilat T, Hacohen D, Lilos P Langman MJ. Childhood factors in ulcerative colitis and Crohn's disease. An international cooperative study. Scand J Gastroenterol 1987;22:1009-24. 
89. Jantchou P, Morois S, Clavel-Chapelon F, Boutron-Ruault MC, Carbonnel F. Animal protein intake and risk of inflammatory bowel disease: The E3N prospective study. Am J Gastroenterol 2010;105:2195-201.

90. Abubakar I, Myhill DJ, Hart AR, et al. A case-control study of drinking water and dairy products in Crohn's disease - further investigation of the possible role of Mycobacterium avium paratuberculosis. Am J Epidemiol 2007;165:776-83.

91. Buning C, Ockenaga J, Kruger S, et al. The C/C (-13910) and G/G (-22018) genotypes for adult-type hypolactasia are not associated with inflammatory bowel disease. Scand J Gastroenterol 2003;38:538-42.

92. Nolan DJ, Han DY, Lam WJ, Morgan AR, Fraser AG, Tapsell LC. Genetic adult lactase persistence is associated with risk of Crohn's disease in a New Zealand population. BMC Res Notes 2010;3:339-43.

93. Kettunen J, Silander K, Saarela O, et al. European lactase persistence genotype shows evidence of association with increase in body mass index. Hum Mol Genet 2010;19:1129-36.

94. Chen M, Pan A, Malik VS, Hu FB. Effects of dairy intake on body weight and fat: meta-analysis of randomized controlled trials. Am J Clin Nutr 2012;96:735-47.

95. Louie JC, Flood VM, Rangan AM, et al. Higher regular fat dairy consumption is associated with lower incidence of metabolic syndrome but not type 2 diabetes. Nutr Metab Cardiovasc Dis 2013;23:816-21.

96. Birlouez-Aragon I, Ravelontseheno L, Villate-Cathelineau B, Cathelineau G, Abitbol G. Disturbed galactose metabolism in elderly and diabetic humans is associated with cataract formation. J Nutr 1993;123:1370-6.

97. Nicklas TA, Haiyan Q, Hughes SO, et al. Self-percieved lactose intolerance results in lower intakes of calcium and dairy foods and is associated with hypertension and diabetes in adults. Am J Clin Nutr 2011;94:191-8.

98. Nettleton JA, Steffen LM, Loehr LR, Rosamond WD, Folsom AR. Incident heart failure is associated with lower whole-grain intake and greater high-fat dairy and egg intake in the Atherosclerosis Risk in Communities (ARIC) study. J Am Diet Assoc 2008;108:1881-7.

99. Huth PJ, Park KM. Influence of dairy product and milk fat consumption on cardiovascular disease risk: A review of the evidence. Adv Nutr 2012;3:266-85.

100. Louie JC, Flood VM, Burlitsky G, Rangan AM, Gill TP, Mitchell P. Dairy consumption and the risk of 15-year cardiovascular disease mortality in a cohort of older Australians. Nutrients 2013;5:441-54.

101. Garland CF, Garland FC. Do sunlight and vitamin D reduce the likelihood of colon cancer? Int J Epidemiol 1980;9:227-31.

102. Grant WB. A meta-analysis of second cancers after a diagnosis of non-melanoma skin cancer: Additional evidence that solar ultraviolet $-B$ irradiance reduces the risk of internal cancers. J Steroid Biochem Mol Biol 2007;103:668-74.

103. Mohr SB, Garland CF, Gorham ED, Grant WB, Garland FC. Ultraviolet $\mathrm{B}$ and incidence rates of leukemia worldwide. Am J Prev Med 2011:41:68-74.

104. Simpson S Jr, Blizzard L, Otahal P, Van der Mei I, Taylor B. Latitude is significantly associated with the prevalence of multiple sclerosis: A meta-analysis. J Neurol Neurosurg Psychiatry 2011;82:1132-41.

105. Zitterman A. Vitamin D in preventive medicine: Are we ignoring the evidence? Br J Nutr 2003;89:552-72.

106. Cantorna MT, Mahon BD. Mounting evidence for vitamin D as an environmental factor affecting autoimmune disease prevalence. Exp Biol Med (Maywood) 2004;229:1136-42.

107. International Agency for Research Group. Dietary fiber, transit time, faecal bacteria, steroids, and colon cancer in two Scandinavian populations. Lancet 1977;2:207-11.

108. Nanji AA, Denardi FG. Primary adult lactose intolerance protects against development of inflammatory bowel disease. Med Hypotheses 1986;19:1-6.
109. Itan Y, Powell A, Beaumont MA, Burger J, Thomas MG. The origins of lactase persistence in Europe. PLoS Comput Biol 2009;5:e1000491. doi:10.1371/journal.pcbi.1000491.

110. Babu J, Kumar S, Babu P, et al. Frequency of lactose malabsorption among healthy southern and northern Indian populations by genetic analysis and lactose hydrogen breath and tolerance tests. Am J Clin Nutr 2010;91:140-6.

111. Heyer E, Brazier L, Segurel L, et al. Lactase persistence in central Asia: Phenotype, genotype, and evolution. Hum Biol 2011;83:379-92.

112. Gallego Romero I, Basu Mallick C, Liebert A, et al. Herders of Indian and European cattle share their predominant allele for lactase persistence. Mol Biol Evol 2012;29:249-60.

113. Peyrin-Biroulet I, Oussalah A, Bigard M-A. Crohn's disease: The hot hypothesis. Med Hypotheses 2009;73:94-6.

114. Garg M, Lubel JS, Sparrow MP, Holt SG, Gibson PR. Review article: Vitamin D and inflammatory bowel disease - established concepts and future directions. Aliment Pharmacol Ther 2012;36:324-44.

115. Ng Sc, Bernstein CN, Vatn MH, et al. Geographical variability and environmental risk factors in inflammatory bowel disease. Gut 2013;62:630-49.

116. Abraham C, Cho JH. Inflammatory bowel disease. N Engl J Med 2009;361:2066-78.

117. Ananthakrishnan AN, Hailiang H, Nguyen DD, Sauk J, Yajnik V, Xavier RJ. Differential effect of genetic burden on disease phenotypes in Crohn's disease and ulcerative colitis: Analysis of a North American cohort. Am J Gastroenterol 2014;109:395-400.

118. Lees CW, Barrett JC, Parkes M, Satsangi J. New IBD genetics: Common pathways with other diseases. Gut 2011;60:1739-53.

119. Itan Y, Jones BL, Ingram CJE, Swallow DM, Thomas MG. A worldwide correlation of lactase persistence phenotype and genotypes. BMC Evolutionary Biol 2010;10:36 < www.biomedcentral. com/1471-2148/10/36> (Accessed March 6, 2015).

120. Molodecky NA, Soon IS, Rabi D, et al. Increasing incidence and prevalence of the inflammatory bowel diseases with time, based on a systematic review. Gastroenterology 2012;142:46-54.

121. Szilagyi A, Leighton H, Burstein B, Xue X. Latitude, sunshine, and human lactase phenotype distributions may contribute to geographic patterns of modern disease: The inflammatory bowel disease model. Clin Epidemiol2014;6:183-98.

122. Gasche C, Nemeth M, Grundtner P, Willheim-Polli C, Ferenci P, Schwarzenbacher R. Evolution of Crohn's disease-associated Nod2 mutations. Immunogenetics 2008;60:115-20.

123. Naser SA, Arce M, Khaja, et al. Role of ATG16L, NOD2 and IL23R in Crohn's disease pathogenesis. World J Gastroenterol 2012;18:412-24.

124. Alfonso-Sanchez MA, Perez-Miranda AM, Garcia-Obregon S, Pena JA. An evolutionary approach to the high frequency of the delta F508 CFTR mutation in European populations. Med Hypotheses 2010;74:989-92.

125. Modiano G, Ciminellui BM, Pignatti PF. Cystic fibrosis and lactase persistence: A possible correlation. Eur J Hum Genet 2007;15:255-9.

126. Madry E, Fidler E, Sobczynska-Tomaszewska A, et al. Mild CFTR mutations and genetic predisposition to lactase persistence in cystic fibrosis. Eur J Hum Genet 2011;19:748-52.

127. Truedsson M, Carlson J, Simren M, Ohlsson B. Polymorphism in the oxytocin promoter region in patients with lactase non-persistence is not related to symptoms. BMC Gastroenterol 2009;9:90-107.

128. Sacerdote C, Guarrera S, Smith GD, et al. Lactase persistence and bitter taste response: Instrumental variables and Mendelian randomization in epidemiologic studies of dietary factors and cancer risk. Am J Epidemiol 2007;166:576-81.

129. Wu GD, Chen J, Hoffmann C, et al. Linking long-term dietary patterns with gut microbial enterotypes. Science 2011;334:105-8.

130. Arumugam M, Raes J, Pelletier E, et al. Enterotypes of the human gut microbiome. Nature 2011;473:174-80.

131. Hecht G. AGA's approach to the microbiome. 2014;146:1119-21. 


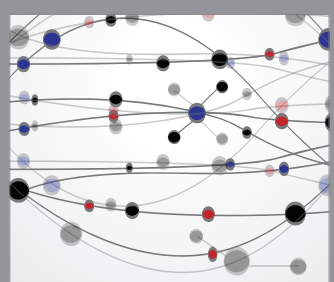

The Scientific World Journal
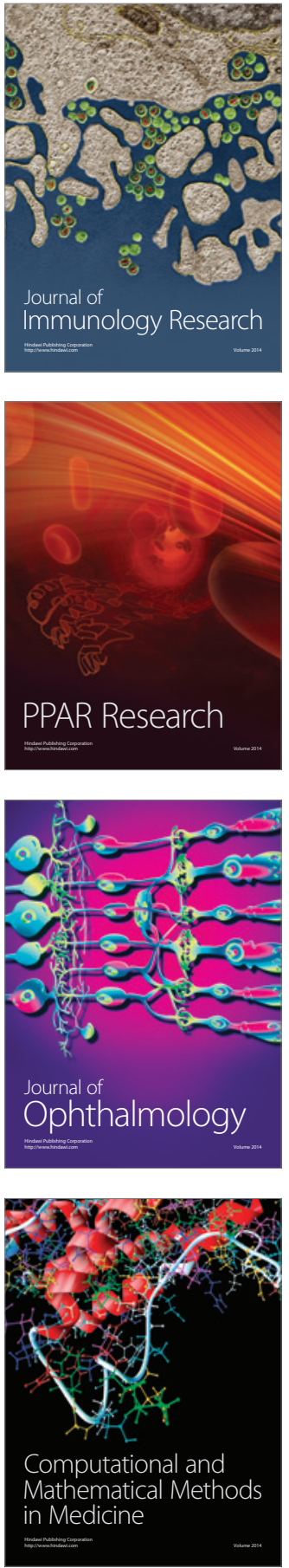

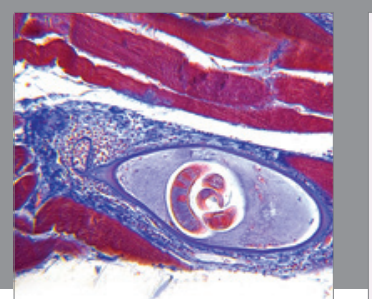

Gastroenterology Research and Practice

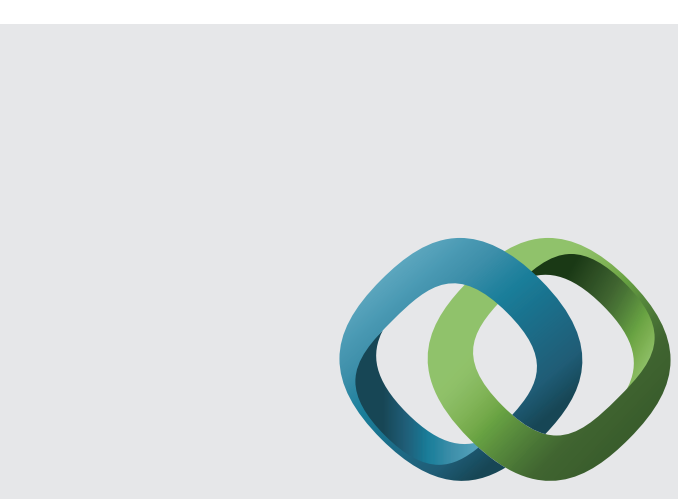

\section{Hindawi}

Submit your manuscripts at

http://www.hindawi.com
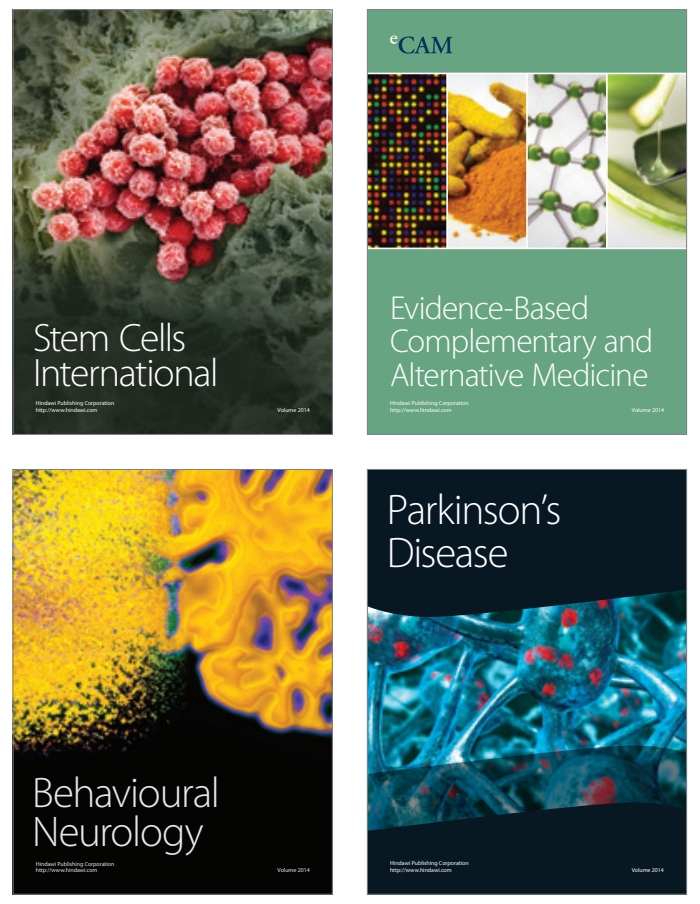
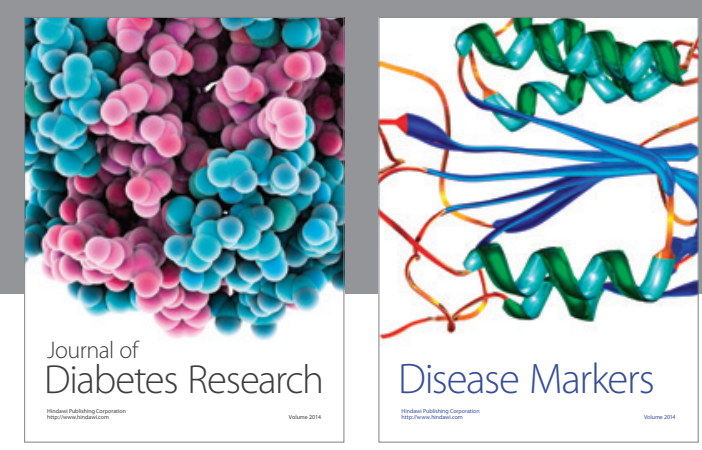

Disease Markers
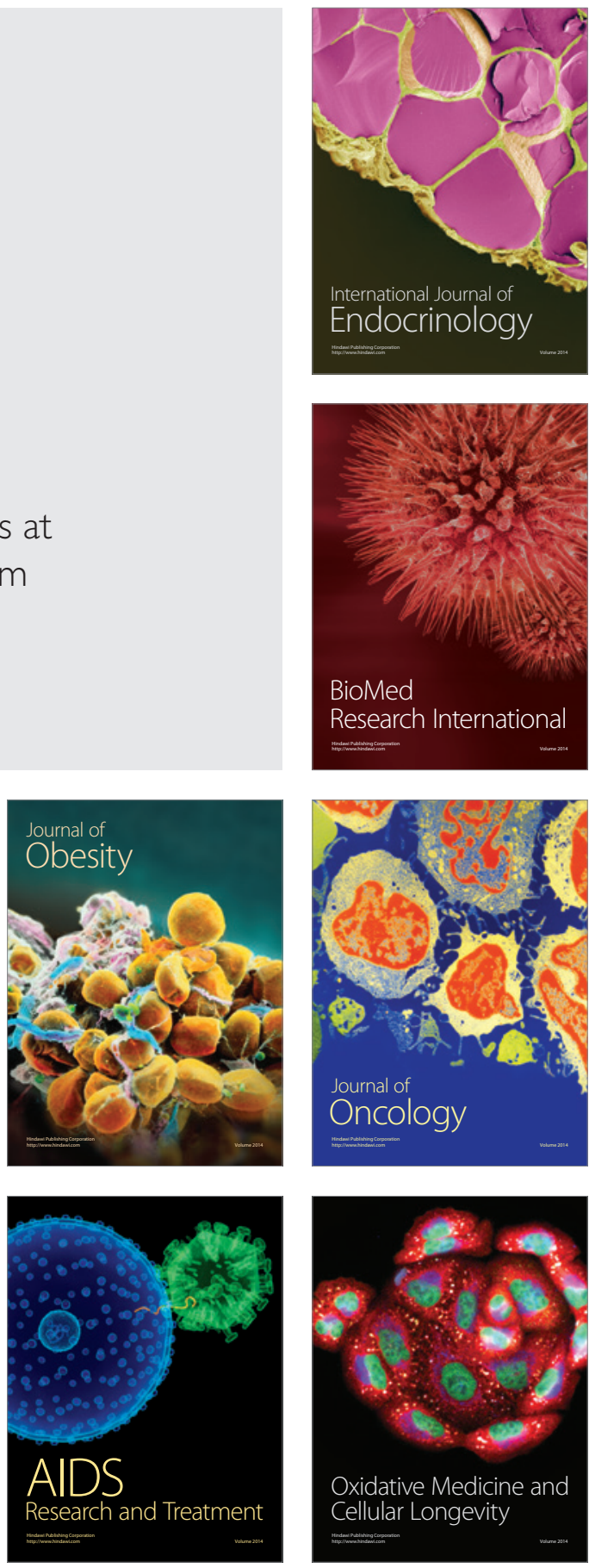